\title{
JOVENS ATIVISTAS DAS PERIFERIAS: EXPERIÊNCIAS E ASPIRAÇÕES SOBRE O MUNDO DO TRABALHO ${ }^{1}$
}

\author{
Maria Carla Corrochano² \\ Raquel Souza ${ }^{3}$ \\ Helena Abramo ${ }^{4}$
}

\begin{abstract}
Resumo
O artigo evidencia como experiências de trabalho, formação e ação coletiva afetam as percepções e aspirações de jovens ativistas sobre o trabalho. Baseia-se em pesquisa qualitativa realizada com participantes de coletivos juvenis de quatro regiões metropolitanas do Brasil. Ainda que o trabalho não figure como eixo central de suas experiências de ação coletiva, está presente em seu universo de preocupações e demandas. Suas vivências possibilitam a crítica das ocupações disponíveis para as jovens gerações e a busca por percursos profissionais aliados à transformação da realidade em que vivem.
\end{abstract}

Palavras-chave: Jovens; Ação Coletiva; Trabalho; Educação.

\section{JÓVENES ACTIVISTAS DE LAS PERIFERIAS: EXPERIENCIAS Y ASPIRACIONES SOBRE EL MUNDO DEL TRABAJO}

\section{Resumen}

El artículo evidencia cómo las experiencias de trabajo, formación y acción colectiva afectan las percepciones y aspiraciones de jóvenes sobre el trabajo. Se basa en investigación realizada con participantes de colectivos juveniles de cuatro regiones metropolitanas de Brasil. Aunque el trabajo no figura como eje central de sus experiencias de acción colectiva, está presente en su universo de preocupaciones y demandas. Sus vivencias posibilitan la crítica de las ocupaciones disponibles para las jóvenes generaciones y la búsqueda por trabajos aliados a la transformación de la realidad.

Palabras clave: Jóvenes; Accion Colectiva; Trabajo; Educación.

\section{YOUNG ACTIVISTS FROM THE PERIPHERIES: EXPERIENCES AND ASPIRATIONS CONCERNING THE WORK WORLD}

\section{Abstract}

The article shows how work, education and collective action experiences affect the perceptions and aspirations of young concerning work. It is based on a qualitative research carried out with youth groups members from four Brazilian metropolitan regions. Although work does not figure as a central axis of

${ }^{1}$ Recebido em 01/04/2019. Primeira avaliação: 15/04/2019. Segunda avaliação: 17/05/2019. Aprovado em 20/06/2019. Publicado em 04/07/2019. DOI: https://doi.org/10.22409/tn.17i33.p29373. 2Doutora em Educação pela Universidade de São Paulo (2008), professora do Departamento de Ciências Humanas e Educação e do Programa de Pós-Graduação em Educação da Universidade Federal de São Carlos (UFSCar) - Sorocaba (SP), Brasil. E-mail: carla.corrochano@gmail.com ORCID: https://orcid.org/0000-0001-8030-6461

${ }^{3}$ Doutora em Educação da Faculdade de Educação da Universidade de São Paulo (FE-USP) - São Paulo (SP), Brasil. E-mail: raqsou@gmail.com. ORCID: https://orcid.org/0000-0001-9588-6729

${ }^{4}$ Socióloga da Secretaria Municipal de Cultura de São Paulo. São Paulo, Brasil. E-mail: hwabramo@yahoo.com.br. ORCID: https://orcid.org/0000-0001-5669-5946 
their collective action, it is present in their universe of concerns and demands. Their experiences make possible the criticism of the available occupations for young generations, as well as the search for professional paths allied to the transformation of the reality in which they live.

Keywords: Young people; Collective Action; Work; Education

\section{Introdução}

Este artigo é resultado de uma pesquisa qualitativa realizada com 21 jovens pertencentes às camadas populares e que participam de diferentes coletivos nas periferias de quatro regiões metropolitanas: São Paulo, Rio de Janeiro, Recife e Distrito Federal, integrando o projeto Juventude nas Cidades ${ }^{5}$. Trata-se de compreender em que medida suas experiências de escolarização e trabalho e sua participação em coletivos provocam alterações nos sentidos e aspirações que nutrem em relação ao mundo do trabalho.

A relação entre jovens e ações coletivas tem sido objeto de estudos nos campos da educação e das ciências sociais há pelo menos três décadas no Brasil. Ao longo desse período, intensificaram-se esforços de análise da capacidade de ação dos atores jovens, em confronto com as recorrentes leituras da juventude como hedonista, apática e desinteressada da vida social e política. Tratava-se de tornar evidente seus múltiplos engajamentos públicos, para além do movimento estudantil, contemplando tanto novas formas e locais de ativismo e práticas coletivas quanto a participação de jovens oriundos de diferentes estratos sociais (ABRAMO, 1994; SPOSITO, 2014).

Desde o conjunto heterogêneo de manifestações ocorridas em 2013, com intensa presença de jovens e coletivos juvenis, oriundos de diferentes lugares sociais, a compreensão das relações entre jovens e ações coletivas defronta-se com novas questões (BRINGEL; PLEYERS, 2013; GOHN, 2018). As várias formas de mobilização, ao lado de ocupações de espaços públicos (ruas, escolas, universidades), levaram à ampliação de pesquisas e a formulação de novas perguntas nesse campo, inclusive em função da diversidade de pautas, pertencimentos e orientações desses movimentos. Assim, ao lado de pautas e de demandas por ampliação de direitos sociais e civis e de reação à implementação de políticas públicas

50 projeto "Juventude nas Cidades" foi implementado por uma rede de organizações (Ação Educativa, Criola, Fase, Ibase, Inesc, Instituto Polis) e coordenado pela Oxfam Brasil, com objetivo de fortalecer a capacidade de protagonismo, inserção e participação social de jovens engajados em ações coletivas. O projeto alcançou cerca de 150 jovens que atuavam nas periferias das regiões mencionadas. 
marcadas por autoritarismo e arbitrariedades em diferentes setores (CORROCHANO; DOWBOR; JARDIM, 2018), também se observam movimentos conservadores, com pautas de liberalismo econômico, preferência por um Estado mínimo e bloqueio a direitos e políticas que reconheçam as especificidades de populações mais suscetíveis à discriminação e exclusão (MARTINS; GROPPO; BARBOSA, 2018, PLEYERS; BENAVIDES, 2018).

Apesar da importância de incluir a análise de ações coletivas marcadas pelo conservadorismo nas agendas de pesquisa sobre educação e juventude, o foco deste artigo recairá sobre jovens engajados em ações coletivas de caráter progressista. Entre esses coletivos observa-se uma pauta diversificada, dentre as quais sobressaem o combate ao racismo e ao machismo/sexismo, a luta pelo acesso e garantia de direitos, entre outras. Pouco se sabe, no entanto, das experiências e aspirações ${ }^{6}$ desses jovens em relação ao mundo do trabalho.

Esta não é uma questão trivial. A despeito das transformações recentes nos nexos entre educação e trabalho para as jovens gerações, com ampliação de sua presença na escola, há tempos reconhece-se que no Brasil o trabalho também faz parte da condição juvenil (SPOSITO, 2005). Soma-se a isso a interrupção de um processo de reestruturação do mercado de trabalho que vinha se configurando há pelo menos uma década (Leite e Salas, 2014). No atual contexto, o desemprego volta a alcançar índices elevados, amplia-se a precarização dos contratos e das condições de trabalho e diminui o valor real do salário mínimo, com implicações significativas para a redução das desigualdades. Os jovens são mais afetados, nesta realidade atravessada por assimetrias de classe, gênero e étnico/raciais (CORROCHANO; ABRAMO; ABRAMO, 2017).

Pontuar as relações específicas vividas pelos jovens no mercado de trabalho não significa, porém, reduzir o conceito de trabalho ao emprego - forma específica assumida pelo trabalho no capitalismo. O trabalho é compreendido como dimensão central da vida humana, "forma de o ser humano criar e recriar seus meios de vida" (Frigotto, 1994, p. 181).Também se consideram as contribuições dos estudos

\footnotetext{
${ }^{6}$ Optamos pelas expressões "aspirações" e "expectativas" para fazer menção às perspectivas de inserção laboral e profissionalização. A escolha parece adequar-se à tarefa de descrever os dados empíricos, compostos por narrativas de jovens que apresentam planos de futuro mais estruturados e outros com horizontes mais imprevisíveis. Evita-se a noção de "projeto de vida", acionada em contextos heterogêneos e de forma polissêmica, mas reiterando a premissa de que competiria ao indivíduo encontrar alternativas para enfrentar desafios estruturais e responsabilizar-se pelo próprio sucesso frente a estes desafios (MARTUCCELLI, 2007).
} 
feministas para o enriquecimento do conceito de trabalho: "de simples produção de objetos, de bens, o trabalho se transforma naquilo que alguns chamam de produção do viver em sociedade" (KERGOAT, 2016, p. 12), contemplando assim o trabalho doméstico, de produção de seres humanos, de cuidado, além do trabalho cooperativo e do militante. O trabalho produz e ao mesmo tempo é produto de uma sociedade, sendo perpassado por diferentes relações sociais, tais como as relações de classe, de raça, de etnia, de sexo/gênero e de idade (SOARES, 2011).

Quais as experiências de trabalho desses jovens ativistas? Em que medida a experiência de militância provoca alterações nas suas aspirações e percepções em relação ao trabalho? O trabalho se configura como pauta relevante para esses coletivos ou, pelo menos, para os indivíduos que os compõem? São indagações que permearam o diálogo com os jovens.

\section{Interfaces entre educação, trabalho e ação coletiva}

Nos últimos 15 anos, importantes transformações no campo da educação impactaram a vida dos jovens brasileiros, inclusive daqueles historicamente alijados do direito de acessar a escola e de nela permanecer por um período mais longevo. A despeito de persistentes indicadores de exclusão escolar e de desafios relacionados à qualidade do ensino, há relativo consenso de que nos deparamos com uma geração de jovens sensivelmente mais escolarizada, consequência direta de um progressivo (ainda que moroso) processo de expansão da oferta pública escolar, iniciado no final da década de 1980, que resultou na quase universalização do acesso ao ensino fundamental e na massificação do ensino médio. Nas duas últimas décadas, no entanto, foi o acesso ao ensino superior que experimentou um movimento substancial de expansão, ainda que com consequências tênues para o perfil educacional da população jovem.

Entre 2000 e 2017, as matrículas em cursos de graduação saltaram de 2,6 milhões para 6,5 milhões, crescimento de 142,4\%. No mesmo período, a frequência líquida de jovens de 18 a 24 anos no ensino superior registrou aumento de 14 pontos percentuais, passando de 9,2\% para 23,2\% (BRASIL, 2018). Este fenômeno pode ser

compreendido como tributário de pressões heterogêneas que induziram a conformação de iniciativas governamentais - bolsas, reserva de vagas, financiamento 
estudantil - destinadas a assegurar maior inclusão e equidade no ensino superior; ao mesmo tempo, a proliferação de vagas e instituições educativas privadas que passaram a ofertar este nível de ensino ${ }^{7}$.

No que diz respeito à presença do trabalho no universo de vivências juvenis, as pesquisas reiteram que este é um domínio central na vida dos jovens, mobilizando expectativas ou requerendo intenso engajamento individual (PAIS, 2001;CORROCHANO, 2012; GUIMARÃES; MARTELETTO; BRITO, 2018). Assim, por mais que a análise da inserção dos jovens no mercado de trabalho e seus impactos mobilizem respostas contrastantes, boa parte dos jovens está em busca de trabalho ou trabalha de maneira precária (SILVA, 2014; GUIMARÃES; MARTELETTO; BRITO, 2018). Isso não significa desprezar que o lugar e os sentidos do trabalho experimentaram importantes inflexões na experiência da atual geração de jovens (SPOSITO; SOUZA, 2014; SOUZA, 2018; NONATO, 2019).

Embora ainda se verifique a existência de jovens das camadas populares que começam a trabalhar antes da idade legal, as estatísticas nacionais têm apontado que alcançar os 18 anos significa chegar à idade em que os brasileiros iniciam suas primeiras experiências laborais. O fenômeno é tributário da própria ampliação do acesso à escola, da reconfiguração das relações entre jovens e adultos na família e, entre 2004 e 2013, da melhoria das condições de trabalho, renda e consumo das camadas populares (CABANAS; KOMATSU; MENEZES FILHO, 2015; SPOSITO; SOUZA; SILVA, 2018). Sobre este último aspecto, é preciso dizer que o afastamento de moças e rapazes mais novos do mercado de trabalho parece persistir mesmo frente à recessão e ao recrudescimento do desemprego, como o experimentado neste momento no Brasil, o que certamente tem demandado esforços substantivos de famílias e indivíduos pertencentes às frações mais empobrecidas.

Dados da Pesquisa Nacional por Amostra Domiciliar Contínua (PNADC) indicam que $78,3 \%$ das moças e rapazes da faixa etária de 15 até 17 anos dedicavamse, em 2017, apenas aos estudos, enquanto outros $10,3 \%$ conciliavam estudo e trabalho. Assim, entre jovens-adolescentes é predominante a presença de estudantes, sendo a escola, ainda que não exclusivamente, a principal instituição a cadenciar suas

\footnotetext{
${ }^{7}$ Não é intuito do artigo problematizar a natureza dessas iniciativas, questão abordada por pesquisas que mostram como elas atenuaram a sub-representação de determinados segmentos entre a população universitária, mas produziram novas facetas de desigualdade e assimetria, além de atender a interesses do mercado (MOEHLECKE, 2004; CARVALHO, 2011; ALMEIDA, 2014).
} 
rotinas e experiências. Tal afirmação não se estende à realidade de jovens de 18 a 24 anos e, sobretudo, daqueles de 25 a 29 anos, faixas focalizadas neste artigo, para a maioria dos quais a experiência laboral é parte da condição juvenil. Nestes dois grupos etários, respectivamente, apenas $21,5 \%$ e 5,4\% destinavam seu tempo somente aos estudos (BRASIL, 2018).

Neste quadro de mudanças, as pesquisas têm registrado a emergência de novas subjetividades e necessidades vocalizadas pela atual geração de jovens. Para além das mudanças de times nos processos de transição escola-trabalho, essa produção assinala como a maior permanência e acesso à escola vem produzindo no Brasil aquilo que Bourdieu, em seu famoso texto Juventude é apenas uma palavra, reconhece como uma das funções fundamentais da instituição: a "manipulação das aspirações".

Bourdieu (2003) explicita que a escola não é simplesmente um lugar em que são aprendidas certas coisas, saberes e técnicas, mas uma instituição capaz de "conferir aos que passam por ela títulos, ou seja, direitos e, nesse ato, também um conjunto de anseios e pretensões" (p.155-6). Entre as expectativas, destaca-se aquela partilhada por jovens e famílias populares, de que o sistema escolar assegure o que outrora promoveu a uma população que se beneficiava do privilégio de uma escolarização mais longeva.

De fato, a emergência de políticas de inclusão e equidade no acesso ao ensino superior - como reserva de vagas em instituições públicas ou bolsas de estudos para estabelecimentos privados - tem sido assinalada como propulsora de mobilidade laboral e social entre jovens das camadas populares. Estudo de Tartuce (2010) mostra como o ingresso em um curso de graduação suscita o desejo de conquistar um posto de trabalho "na área". Por trás do anseio em estabelecer uma correlação entre o curso frequentado e a inserção laboral em determinado setor expressa-se a vontade dos jovens de exercer controle sobre seus processos de integração social, ou seja, a expectativa de estruturar uma experiência no mundo do trabalho em que não percam de vista as especificidades de suas histórias e singularidades.

Considerando que as experiências escolares desses jovens podem produzir alterações em suas aspirações no campo do trabalho, o que dizer de suas experiências de ação coletiva? Como será visto, os jovens investigados não estavam engajados em formas mais tradicionais de agregação coletiva, como sindicatos ou 
partidos (SPOSITO, 2014) ou movimentos mais consolidados e institucionalizados, como o movimento estudantil, mas em coletivos - reunidos em torno de um projeto ou atividade que compartilhavam ou consideravam relevantes (REGUILLO, 2003).

Os coletivos juvenis considerados eram grupos em busca de estratégias cotidianas para enfrentar discriminações e dificuldades econômicas e sociais. Vários desses jovens também se engajaram em manifestações, mobilizações e ocupações de escolas, universidades e prédios públicos que aconteceram entre 2015 e 2016. Optamos pelo conceito de ação coletiva para caracterizar as suas práticas e experiências, decisão que se ancora no debate teórico que argumenta pela necessária distinção entre diferentes formas de ação coletiva e movimentos sociais enquanto categorias de análise.

Sobre esse aspecto, importa considerar as reflexões de Melucci (2001, p. 358), para quem as condutas de resistência e luta podem não conter elementos que as caracterizem como movimentos sociais. Para o autor, os elementos constitutivos de um movimento social seriam: a capacidade de estabelecer um conflito, de identificar um "nós" a partir desse conflito, e a totalidade, ou seja, a capacidade de acenar para uma ruptura e uma nova maneira de constituição das relações sociais. Ademais, as dificuldades em caracterizar suas ações como movimento social residem nos próprios limites do conceito, diante da emergência de um conjunto amplo e variado de ações e "insurreições" que irromperam na cena pública no século XXI, no Brasil e em outras partes do mundo. Como afirma Reguillo (2017, p. 3):

Movimentos em rede, insurgências de novo cunho, novíssimos movimentos sociais, expressões de mal-estar contemporâneo, são e serão formulações inacabadas, titubeantes, imperfeitas para nomear e compreender mais profundamente o que se move por baixo das camadas visíveis de \#OccupyWallStreet, \#YoSoy 132, \#15M, \#NuitDebout, \#PasseLivre e outras expressões que de norte a sul, de sul a norte têm reclamado seu lugar na história.

As perguntas formuladas para os jovens também ancoraram-se em uma perspectiva analítica que considera a importância do olhar para as ações coletivas e para os movimentos sociais não apenas em seus impactos na política institucional. Sem ignorar a relevância das ações dirigidas ao Estado, trata-se de contemplar "as transformações nas subjetividades e comportamentos na vida cotidiana, na esfera profissional e no espaço público" (PLEYERS; BENAVIDES, 2018, p. 3). 
Cabe considerar que, embora o trabalho persista como dimensão relevante e objeto de preocupação das jovens gerações, a demanda por trabalho ou por outro trabalho não emerge com força no espaço público no Brasil, mesmo considerando as mobilizações recentes, diversamente do que ocorre em outros países (FERREIRA, 2017). Pode-se tentar explicar essa ausência em função do acirramento do neoliberalismo, que gera nos sujeitos a percepção de que são responsáveis individualmente e a partir de suas próprias decisões por seus sucessos e fracassos, especialmente quanto ao trabalho (REGUILLO, 2017; DUBET, 2002). No Brasil, esse processo parece mais intenso e a tônica do "se virar" para ganhar a vida, atualmente nomeada como "empreender", ganha força (TOMMASI; VELAZCO, 2013).

\section{Breve descrição da pesquisa e dos jovens interlocutores}

A pesquisa, de caráter qualitativo e fazendo uso de entrevistas compreensivas (KAUFFMAN, 1996), foi realizada entre 2017 e 2018. Foram entrevistados 21 jovens moradores de quatro regiões metropolitanas: São Paulo, Rio de Janeiro, Recife e Distrito Federal. Todos participavam de heterogêneos coletivos juvenis - 18 no total e, na época do trabalho de campo, integravam uma rede tecida em torno do projeto “Juventude nas Cidades". Dados os limites deste artigo, não serão apresentadas as diferenças em relação à atuação dos jovens em cada uma das regiões, tampouco nos ateremos aos objetivos e resultados alcançados pelo projeto de que faziam parte. Trata-se aqui de concentrar esforços em torno dos imbricamentos entre as experiências de escolarização, trabalho e militância em que estavam engajados.

A escolha dos entrevistados foi realizada com o apoio das organizações que participavam do projeto, que também cederam espaço para os diálogos em cada uma das cidades. Na perspectiva de abarcar a diversidade juvenil, foram entrevistadas pessoas com ou sem filhos e com diferenças quanto a gênero e orientação sexual, raça e etnia, escolaridade, idade no tempo da juventude e situação no mercado de trabalho.

As entrevistas contaram com intensa participação e engajamento dos jovens. As conversas duraram em média duas a três horas e foram marcadas por muita emoção. Por vezes, foi preciso interromper a gravação para dar tempo ao silêncio, às lágrimas, às palavras entrecortadas. Em outros momentos, a necessidade de não 
apenas falar, de responder a perguntas, mas de também ouvir e discutir com as entrevistadoras temas relevantes de suas trajetórias e do País, ganhou força. Também aconteceu de demandarem um tempo maior para explanarem sobre sua visão de mundo e o tema de atuação dos coletivos. A análise dos resultados considerou o procedimento indutivo, aproximando-se da perspectiva de Demazière e Dubar (1997). Ainda que não tenha sido realizada uma análise discursiva, o trabalho analítico realizado deu especial atenção para os conteúdos, as maneiras de falar e o contexto da enunciação.

Os relatos deixam entrever que as motivações para organização em coletivos, bem como os temas de atuação desses jovens eram diversos: passaram a se organizar a partir de ações no bairro ou na escola, na perspectiva de mudança da realidade local - neste caso, as ocupações de escolas e universidades tiveram papel relevante; ouse reuniam em lutas por reconhecimento (HONNET, 2003), realizando ações e debates em torno de temas como combate ao racismo, valorização da negritude, denúncia do machismo e sexismo, demandas e direitos da população LGBTQ+. Havia também coletivos organizados em torno da cultura, da saúde, da sexualidade adolescente e jovem, além dos temas da comunicação, moradia e meio ambiente. No total de coletivos dos quais os entrevistados faziam parte (18), apenas dois estavam estruturados em torno da busca de geração de renda. As formas de organização dos coletivos também eram variadas, mas, à semelhança do que vários estudos têm observado entre grupos e movimentos juvenis, a valorização da ação direta, da horizontalidade, das rodas de conversa e diálogo entre pares, bem como 0 rechaço à constituição de lideranças, estavam presentes (GOHN; BRINGEL, 2012; CORTI; CORROCHANO, SILVA, 2016; SILVA, 2018).

O perfil etário dos entrevistados corresponde à categoria juventude, entre $15 \mathrm{e}$ 29 anos, conforme estabelecido pelo Estatuto da Juventude. Cabe ressaltar que todos tinham mais de 18 anos, momento da vida juvenil em que o trabalho se torna muito presente, como revelam as estatísticas nacionais. Dialogamos com 12 mulheres, uma mulher transexual, e oito homens, sendo 18 jovens autodeclarados pretos, dois indígenas e uma jovem que se declarou mestiça.

Em termos de condição socioeconômica, todos pertenciam às camadas populares, categoria mobilizada neste artigo para referirmo-nos tanto a indivíduos pertencentes a famílias pobres quanto àqueles que, dadas as situações contingentes 
de moradia, acesso à educação, integração ao mundo do trabalho e aos mercados de consumo, conformam gradações situacionais no interior de uma mesma posição social (Souza, 2018). Muitos desses jovens apresentavam-se no momento da entrevista como "preto/a e periférico/a". Segundo Nascimento (2014), muito embora o modelo dicotômico centro-periferia seja objeto de críticas no âmbito acadêmico, em função da heterogeneidade de situações observáveis nesses espaços, é relevante destacar a pertinência do termo periferia para referir-se a determinadas realidades que concentram populações marginalizadas econômica, racial e socialmente.

Pode-se dizer que os sujeitos da pesquisa se beneficiaram das políticas públicas voltadas para ampliação da escolarização no Brasil, como apontado. Apenas dois jovens ainda cursavam o ensino médio e quatro completaram esse nível de ensino, embora não tenham prosseguido os estudos. A grande maioria alcançou o ensino superior: cinco já haviam concluído seus cursos (Direito, Arquitetura, Artes Visuais, Enfermagem, Pedagogia), cinco eram estudantes de graduação (Serviço Social e Psicologia) e cinco haviam interrompido os estudos por razões financeiras. Cabe destacar que dois estudantes no Rio de Janeiro e dois no Recife frequentavam universidades públicas, tendo participado do processo de ocupação desses espaços em 2016.

Com exceção de um único jovem, que se dedicava exclusivamente à conclusão do ensino médio, o trabalho e a busca por trabalho é parte da realidade dessas moças e rapazes. Uma parcela encontrava-se desempregada (sete jovens), mas o cotidiano era marcado por muita atividade: não apenas em torno da busca por trabalho, mas por "bicos" ou "freelas", ou múltiplas tentativas de emplacar um "corre" ou gerar renda a partir das atividades de seus coletivos. Esses dados corroboram pesquisa de Guimarães, Hirata e Sugita (2009): diversamente do que se observa em países que construíram mecanismos mais sólidos de seguridade social, a relação com o desemprego no Brasil é construída em torno do trabalho, mais do que da privação do emprego. Apenas dois jovens tinham um emprego formal no momento da pesquisa: uma jovem trabalhava em uma ONG e um jovem em uma corretora de seguros. Os demais trabalhavam com diferentes tipos de vínculo: estágio, iniciação científica, trabalho autônomo ou negócio próprio (tatuagem, massoterapia, serigrafia, grafite). Apenas um se reconhecia como "empreendedor social", ressaltando sua diferença em relação aos empreendedores individuais. 
No geral, a situação dos entrevistados é expressiva da condição juvenil das camadas populares no Brasil: revela um cotidiano marcado por muitas atividades, com os períodos do dia preenchidos por tarefas em múltiplas dimensões: estudo, trabalho, cuidados com a casa e a família, especialmente entre as jovens mulheres; no caso dos jovens aqui considerados, somava-se sua atuação nos coletivos juvenis.

\section{Experiências de trabalho}

Ainda que nenhum dos jovens declare experiência de trabalho ilegal na infância ou início da adolescência, boa parte começou a trabalhar cedo, por volta dos 16 anos, cursando o ensino médio ou logo depois de finalizá-lo. As motivações iniciais para a busca por trabalho são múltiplas: para além da necessidade de apoio à família, a busca por independência e autonomia, a obtenção de renda para estudo e lazer, a conquista de prestígio na família. Reconhecendo-se como jovens moradores de regiões periféricas e filhos de trabalhadores, a entrada no mundo do trabalho é relatada como algo "normal". Seus relatos aproximam-se do observado em várias pesquisas sobre a inserção no trabalho entre jovens de camadas populares (Frigotto, 2004; Guimarães, 2005; Tartuce, 2010; Corrochano, 2012). Ao mesmo tempo, revelam novos marcos, a determinar os modos e as condições para a entrada no mundo laboral: a idade mínima, ficando evidente o esforço de algumas famílias para que a inserção se efetive depois da conclusão do ensino médio, priorizando-se os estudos, e a busca por inserções mais protegidas. Mesmo quando não é possível esperar a conclusão do ensino médio para trabalhar, trata-se de não aceitar "qualquer trabalho".

Ao relatarem suas primeiras experiências de trabalho, quase todos enfatizaram que inicialmente percebiam o trabalho como positivo, com possibilidades de geração de renda, aprendizados e novas amizades. Essa percepção logo se dissipa, em função da experimentação de situações negativas no trabalho, o cansaço e as dificuldades geradas pela extensão da jornada e dos deslocamentos, impondo prejuízos para a continuidade ou qualidade dos estudos e da vida familiar e social.

Nesse sentido, especialmente as ocupações com jornadas de trabalho mais longas, incluindo o trabalho nos finais de semana, são avaliadas de maneira muito negativa. Para além da jornada, atividades estressantes e sujeitas a assédio moral, 
como o trabalho no setor de comércio e serviços, em shoppings e no setor de telemarketing são vistas com muita negatividade, comprometendo a saúde, a possibilidade de estudar, a fruição e o lazer. De fato, o trabalho no setor de serviços, especialmente no telemarketing, é expressão máxima das formas contemporâneas de exploração da força de trabalho e da lógica desumanizadora do capital (BONO; LEITE, 2016; MÉSZÁROS, 2002). O telemarketing também tem se configurado como porta de entrada para jovens, em especial aqueles cujos corpos são comumente excluídos -homossexuais, negros/as, mulheres, gordos/as (BENEVIDES, 2010).

Mesmo quando regidas por vínculos formais, as primeiras ocupações não deixaram de ser problematizadas. Sabe-se que a precariedade no trabalho não pode ser associada apenas à ausência de contratos ou direitos sociais, relacionando-se também com a intensificação de controles, metas e exigências, inclusive de engajamento subjetivo no trabalho (LIMA, 2013); também está relacionada à vivência de discriminação, preconceito e assédios, relacionados às suas características e identidades. A questão do racismo é muito presente, expressa em relação às características do cabelo ou do modo como é penteado, que revela não só as características raciais, mas a identidade assumidamente negra: o cabelo afro, o dreadlock, as tranças. Ser mulher também traz muitas situações de violência e discriminação, principalmente de assédio.

Os elementos negativos do trabalho não são percebidos apenas pelos assalariados, mas também no âmbito dos "corres" e dos empreendimentos. Se por um lado há uma ênfase inicial nos aspectos positivos do trabalho como empreendedor - "trabalhar para si próprio", "não ter patrão", "não se entregar para o mercado", "fazer seu próprio horário" -, as dificuldades ficam evidentes, contemplando seus reflexos nas demais dimensões da vida. A relação com a atividade "por conta própria" é marcada por ambiguidades, como evidenciado por Tommasi e Velazco (2013) em estudo sobre jovens produtores culturais nas favelas.

Não apenas os obstáculos para gerir e sustentar o negócio aparecem com força, como também os limites de tempo para continuidade dos estudos e a vivência de situações de discriminação e humilhação. Alguns buscavam diminuir a insegurança por meio da formalização, na constituição de microempreendimentos individuais (MEI), e outros, especialmente envolvidos no campo da cultura, apontavam como saída a participação em editais públicos, ao mesmo tempo em que denunciavam a 
escassez dessas fontes de financiamento. Para muitos era preciso combinar o trabalho autônomo a "bicos" e "freelas".

As experiências de desemprego e de rotatividade também participam das percepções sobre o trabalho. Alguns jovens decidiram deixar seus empregos porque não suportavam mais as condições, as dificuldades de conciliação com outras dimensões da vida, os baixos salários, as discriminações. A este respeito, sabe-se que a rotatividade é uma característica estrutural do mercado de trabalho brasileiro. Sabe-se também que ela é maior entre os jovens e que, como regra, a circulação por diferentes trabalhos não está relacionada à "irresponsabilidade" ou "imaturidade" juvenil. Em geral os trabalhadores jovens circulam mais no mercado de trabalho por que estão sujeitos a taxas mais elevadas de desemprego (CORSEUIL, 2014). Nesse sentido, é emblemática a lucidez de uma jovem entrevistada sobre a dinâmica das contratações dos jovens nas "empresas de shopping":

\begin{abstract}
Eles mandavam bastante embora e a galera também pedia muito pra sair, só quem queria trabalhar mesmo que tinha que ter o sangue muito frio, porque era muito trabalho, recebia muito pouco, era muita pressão, porque lá as metas são altíssimas, de sessenta mil, setenta mil (...) é emprego de shopping...Todo mundo no shopping tem que bater as metas, senão tá fora, é aquela pressão o tempo todo. E quem trabalha nisso são jovens, pode pesquisar. Eles precisam de mais funcionários e jovem é barato, a gente é barato pra trabalhar. Primeiro emprego, a gente não sabe, lá exige muito e eles podem exigir da gente porque a gente não sabe. (...) E não existe isso (sindicato) nesse lugar, "não tá satisfeito vai embora". Pede demissão ou é demitido (mulher, 22 anos, preta, ensino superior incompleto, Distrito Federal).
\end{abstract}

As trajetórias laborais vão se desenhando em função das contingências e possibilidades existentes, mas também de uma busca de sentido para si e suas expectativas de realização e aspirações: mesmo os primeiros empregos, às vezes aceitos sem muita reflexão, são avaliados e confirmados, ou abandonados, em função do sentido que encontram na sua realização. Isso é mais ou menos possível em função do maior ou menor suporte familiar que possuem: as chances de sair de um trabalho marcado por maior precariedade é maior para aqueles que têm apoio familiar. Ao mesmo tempo, em todas as cidades os relatos também deixaram entrever o papel da conjuntura nas chances de escolha: o cenário econômico mais favorável, com taxas de desemprego menores no momento em que se inseriram, possibilitou alguma margem de escolha sobre sua situação de atividade, o que já aparecia diferente no momento atual em que se encontravam. 
O maior enfrentamento e a problematização das situações vividas nos espaços de trabalho, entretanto, tornam-se mais intensos a partir de suas próprias experiências no trabalho, mas também da ampliação de sua escolarização, sobretudo para aqueles que ingressam no ensino superior, e de suas experiências de militância. Esses elementos contribuem para aprofundar a percepção sobre os direitos e introduzem um olhar ainda mais crítico sobre o trabalho realizado, seu conteúdo e as relações envolvidas: o que antes aparecia como natural revela-se como experiência de opressão e discriminação, levando a reavaliações de estratégias de inserção laboral e a constituição de situações de conflito com empregadores, às vezes resultando em pedidos de demissão, mesmo quando a experiência do trabalho era inicialmente avaliada como positiva:

Era uma delícia trabalhar, eu gostava de trabalhar como aprendiz, de estar fazendo coisas, de... de estar sendo útil, assim... e receber, né? [...]. Mas agora... eu acho completamente errado essa... essa maneira de colocar alguém no mercado e de... porque eu trabalhava por trabalhar, nem sabia o quê que eu estava fazendo, sabe? Eu era uma reprodutora de conteúdo, então só repetia o que me pediam pra eu fazer, não pensava, não... [...] então era um trabalho que não era feito pra você pensar, era feito pra você só reproduzir o que estavam mandando (mulher, 26 anos, preta, ensino superior completo, Recife).

Durante 7 anos foi tudo OK, cabeça alienada, eu era colaboradora, estava ali trabalhando, tudo bonitinho, era uma empresa na qual o colaborador entrava sem bater na porta, me chamava pelo apelido, era uma empresa muito família, era muito tranquilo. Só que, quando eu comecei a fazer a faculdade, isso foi começando a me pesar, com a participação no coletivo também, eu comecei a me incomodar com muitas coisas que estavam acontecendo, com o que eu estava querendo ser para mim mesma [...] porque eu estava muito no automático [...] a felicidade só começava quando eu ia para a faculdade, ou, no fim de semana, quando ia atuar com o coletivo (mulher, preta, 25 anos, ensino superior incompleto, São Paulo).

A ampliação da escolarização, sobretudo a inserção no ensino superior e o engajamento em ações coletivas modificam os olhares para as experiências de trabalho passadas, mas também vão contribuindo para delinear novos sentidos e aspirações para o trabalho do presente e do futuro. 


\section{Experiências múltiplas na fabricação de sentidos e aspirações de trabalho}

Os jovens ativistas assinalam uma diversidade de sonhos de trabalho, com a coexistência de novas aspirações. Entre jovens pertencentes a coletivos culturais, observa-se o desejo de "viver da arte", de se sustentar fazendo o que sabem fazer no campo da expressão artística. Há também o horizonte de estruturar seus próprios empreendimentos, desde que estes Ihes permitam, de alguma forma, estabelecer relações entre atividades laborais e o que realizam no âmbito da ação política ou de sua formação. Existe ainda a perspectiva de trabalhar em órgãos governamentais ou organizações não governamentais (ONGs), fazendo atividades que possam melhorar a vida das pessoas e/ou promover transformação social, na condição de servidores públicos ou de assalariados, à semelhança dos resultados encontrados no estudo de Silva (2018).

Apesar da heterogeneidade, seus depoimentos revelam princípios e referências comuns. Em primeiro lugar, todos compartilham a esperança de escapar de atividades laborais carentes de sentido e reconhecimento. Faz parte das expectativas o acesso ao trabalho ou a formas de geração de renda em que se percebam engajados em atividades que "gostam", que "escolheram" e onde podem obter "algo mais". Assim, os jovens explicitam significações que transcendem um sentido instrumental acordado ao trabalho, o que não significa negligenciá-lo enquanto atividade importante, produtora de recursos necessários para a subsistência deles próprios e de suas famílias.

Todos querem um trabalho que Ihes garanta uma vida digna, sem privações e em condições que não sejam de exploração ou expropriação de seus talentos, ideias e universo de preocupações. Entretanto, reivindicam que a atividade laboral desenvolvida - no presente e no futuro -, ao lado do dinheiro, assegure recompensas de caráter existencial, isto é, que a atividade se conecte aos seus estilos de vida, visões de mundo e projetos políticos e sociais.

Que a gente consiga, entre aspas, milhões de aspas, da palavra trabalho, a gente viva realmente daquilo que a gente quer, ou seja, a gente trabalhe naquilo que a gente escolheu trabalhar. Não porque a gente é obrigado e precisa do maldito dinheiro, mas que o dinheiro só seja a vírgula do texto, que o texto seja mais importante do que a vírgula. Porque há textos maravilhosos sem um monte de vírgula, ou sem vírgula totalmente, e às vezes tem textos que são ruins demais, 
com vírgula, ponto, e com o português muito correto, mas são horríveis (homem, 29 anos, preto, cursando o ensino superior, São Paulo).

Esses testemunhos assemelham-se aos coletados pelo sociólogo português Vitor Ferreira, que tem investigado o anseio de moças e rapazes por estabelecerem, no domínio do trabalho, uma combinação de valores intrínsecos e extrínsecos à atividade profissional, além da perspectiva de converter seus modos de vida e práticas de sociabilidade, expressão, lazer e fruição cultural em formas de ganhar a vida. É com essa perspectiva que argumenta sobre a urgência de "olhar para as práticas desenvolvidas no âmbito das culturas juvenis não apenas como atividades de lazer,

de consumo ou de resistência ideológica", mas igualmente como se processa a apropriação realizada pelos indivíduos dessas como "práticas de produção, com potencial de vir a constituir um meio de vida no futuro" (FERREIRA, 2017, p. 489-90).

Para além de uma significação mais "individualizada", há uma perspectiva bastante comum de construção de um itinerário laboral em que possam construir sua própria "incidência na sociedade". Seus testemunhos ressaltam, de maneira contundente, a finalidade do trabalho que gostariam de realizar: produzir incidência positiva sobre a realidade e, mais precisamente, assegurar a melhoria das condições de vida e experiências de grupos com os quais se identificam.

A perspectiva de atuação profissional "implicada", afinada com aquilo que se realiza no âmbito da ação coletiva, se expressa no horizonte dos jovens de atuarem no desenvolvimento de políticas públicas, de se tornarem professores de escolas públicas, de trabalharem como assistentes sociais em abrigos ou programas de acolhimento de crianças, em organizações de defesa dos direitos humanos, especialmente para negros e LGBTQ+, de trabalhar em órgãos públicos de planejamento urbano e produção de moradias populares.

Mas essa implicação se expressa igualmente entre jovens que, atuando no campo da cultura, da expressão e da difusão artística, tomam a possibilidade de autossuficiência individual e de seus coletivos como uma forma de resistência e ruptura das fronteiras presentes no universo da produção artística. Existir no campo das artes enquanto indivíduo ou grupo figuraria, nesse sentido, como uma ação política e de incidência sobre a realidade de determinado domínio.

O desejo de trabalhar em políticas públicas muitas vezes é formulado como uma ação que cumpre a finalidade de "ocupar" espaços de poder e de decisão que, em sua percepção, contam com uma sub-representação de indivíduos com 
identidades similares: negros, mulheres, periféricos, LGBTQ+ etc. Com essa perspectiva, mais de um entrevistado diz querer ser secretário de Cultura, coordenador municipal de juventude e até mesmo juiz, além de vislumbrar exercer algum cargo legislativo, na condição de vereador ou deputado.

Quem sabe?! Eu pretendo ser (juiz), vou tentar. A gente precisa intervir diretamente nesse judiciário, a gente precisa ter as pessoas do movimento social em todos os âmbitos. Faz-se necessário, porque acho que é uma visão totalmente diferente da outra galera, então se a gente não lutar é complicadíssimo. É uma luta desleal, mas é importante a gente juntar as forças. Porque a galera não quer saber da gente não, quem tá lá em cima não quer saber, então a gente tem que lutar pra ocupar esses espaços que por direito é nosso também, não é um favor (homem, 25 anos, preto, ensino superior completo, Recife).

Como compreender tais aspirações? Nossa hipótese é de que elas parecem ser tributárias de uma articulação sui-generis de suas experiências de escolarização, participação e inserção laboral. No caso desses jovens ativistas da periferia o que modula seus sonhos é uma combinação de experiências e referências obtidas pela

participação no próprio mundo do trabalho, na inserção escolar, principalmente universitária, e na militância. Suas aspirações, expressas no momento da pesquisa, são frutos desses percursos e esferas de circulação combinados. Nas trajetórias vividas no mundo do trabalho vão se construindo as referências do positivo e do negativo, o que orienta as buscas do trabalho satisfatório e possível. As aspirações formadas a partir do alargamento de sua escolaridade também reconfiguram os sonhos, abrindo horizontes antes não visualizados, em termos das áreas de especialização, ou nos empregos em instituições que antes não pareciam acessíveis. O próprio ativismo, que toma parte significativa de suas vidas, e a participação em espaços coletivos de debate e reflexão, vão produzindo modulações em suas percepções sobre o trabalho e dando novas formas às suas aspirações nesse campo. A área de formação técnica e o ativismo estão bastante imbricados na formatação das suas aspirações de trabalho. Um alimenta o outro e ajuda a reorientar ou ajustar os sonhos profissionais. Sabemos que as escolhas dos cursos universitários ou de especializações técnicas são fruto de uma complexa e às vezes fortuita equação entre sonhos de profissionalização e universo de alternativas (Almeida, 2014; Santos, 2018). Nossos entrevistados relatam como vão definindo e redefinindo os cursos a partir de seus desejos, da oferta de cursos públicos em seu 
território ou território acessível, das condições pessoais e familiares de manutenção de uma mensalidade em uma escola particular, das possibilidades de obtenção de uma bolsa ou apoio para manter um curso privado, das chances de entrar em determinados cursos em universidades públicas a partir dos pontos obtidos no ENEM, do tempo e dinheiro que dispõem para fazer cursinhos pré-vestibulares. Mas também as informações e referências obtidas em seus espaços de militância atuam nessas definições.

Mais de um jovem relata o redirecionamento dos planos de fazer um determinado curso para outros cursos, quer porque estes são/foram realizados por pessoas de referência em seus espaços de participação e ação coletiva, quer porque esperam encontrar fundamentos teóricos e práticos que fortaleçam tanto as atividades desenvolvidas por seus coletivos quanto as possibilidades de convertê-las em saber e fazer profissional. Neste sentido, os relatos de nossos jovens reforçam o que já foi demonstrado em outros estudos: os conhecimentos adquiridos na universidade despertam e por outras vezes formatam novas aspirações de trabalho (TARTUCE, 2010; TARABOLA, 2017). Não só a formação escolar, mas os trabalhos nos quais se inserem a partir da universidade (estágios, projetos de extensão, grupos de pesquisa, entidades acadêmicas) contribuem para despertar ou intensificar a dimensão militante e incidir sobre as formas de atuação profissional, no desejo de unir militância e especialização acadêmica. Não por acaso, vários jovens entrevistados expressam intenção de estruturar uma carreira acadêmica, como pesquisador ou professor universitário.

Além de incidir sobre a escolha de uma carreira universitária, a participação em ações coletivas e militância reverberam uma percepção crítica em torno da exploração capitalista. Poucos consideram a alternativa de trabalho assalariado em uma empresa privada que, com frequência, associam a fazer um trabalho sem sentido, tomar posição na "engrenagem do sistema", dar "a sua própria carne" à voracidade capitalista, tornar-se alienado e formatado. Como assinala este jovem autodeclarado preto, de 28 anos, integrante de um coletivo de Recife: "Costumo falar que é o sistema porque é uma engrenagem muito grande. Porque quem trabalha muito tempo chega cansado, e quem chega cansado não pensa, só reproduz". Trabalhar com políticas públicas, em programas de ONGs, nessa perspectiva, representa para estes jovens a 
possibilidade de ascender a ocupações e espaços de trabalho menos marcados por finalidades mercantis e, talvez, por relações mais humanizadas de trabalho.

Parcela significativa dessas moças e rapazes vislumbra outras formas de trabalho, contrapondo-se à lógica do sistema capitalista. A busca por iniciativas em torno dos campos da economia solidária, do cooperativismo e da autogestão é muito presente. Tais horizontes também se assentam sobre uma crítica às condições de atividade laboral encontradas pelos jovens na forma de trabalho assalariado, seja porque dificilmente articulam-se ao conjunto de práticas e de saber-fazer que esperam desenvolver neste domínio, seja porque tais experiências são caracterizadas por eles a partir de suas dimensões de exploração e expropriação.

A alternativa de geração de renda por meio de empreendimentos individuais ou de negócio próprio também esteve presente, mas para uma parcela menor de jovens. Sobre este aspecto, como vem problematizando Tommasi e Velazco (2013), não se deve desprezar o fato de que estes indivíduos estão inseridos em contextos nos quais dispositivos de intervenção social têm sido acionados pelos setores público e privado, que difundem e alimentam o indivíduo empreendedor como ideal de sujeito capaz de lidar com as exigências do capitalismo contemporâneo. Faz parte desses dispositivos tanto a exaltação do que passa a ser apreendido como uma espécie de "essência" das camadas populares, cuja principal riqueza seria sua capacidade criativa, ao lado de incentivos ao empreendedorismo em diferentes âmbitos da vida econômica, social e cultural (TOMMASI; VELAZCO, 2013).

De fato, alguns jovens mantinham relações com organizações não governamentais e com fundações empresariais que, de alguma maneira, incentivavam a organização dos jovens em torno de empreendimentos individuais e, principalmente, coletivos, inclusive como alternativa para enfrentar as dificuldades encontradas para inserirem-se em um mercado laboral cada vez mais restrito e excludente. De toda forma, mesmo entre os que apostavam na via do empreendimento individual, também havia uma visão crítica sobre as condições de trabalho assalariado, o que se desdobrava em uma visão negadora desta forma de engajamento laboral.

Nesse quadro, em vez de investirem em ações sobre as condições e os direitos do trabalho, promove-se a busca por alternativas ao emprego e ao trabalho assalariado, na forma do trabalho autônomo, empreendimento social ou economia 
solidária. Essa faceta não deve ser generalizada a ponto de supor a predominância de um perfil de jovens "empreendedores", ávidos por construir alternativas em que sejam seus próprios patrões ou do predomínio da busca por outras formas de trabalho pela via do cooperativismo ou da economia solidária. Parte expressiva das moças e dos rapazes entrevistados nutre, na verdade, a expectativa de inserir-se na condição de empregados em ONGs e/ou de tornarem-se servidores públicos. Ademais, entre os jovens que partilham a perspectiva de estruturar seu próprio empreendimento, o que parece estar em jogo é a recusa em realizar um trabalho anódino e anônimo, como aqueles mais comumente disponíveis para indivíduos como eles, além de menos suscetível a diferentes formas de exploração percebidas no âmbito do trabalho em instituições privadas.

\section{Considerações finais}

As aspirações e os sentidos atribuídos ao trabalho pelos e pelas jovens ativistas desta pesquisa resultam de uma combinação bastante singular de suas experiências de escolarização, participação e inserção laboral. A possibilidade de alcançar um trabalho digno e com sentido, por meio do qual alcancem uma incidência social e política, reconhecimento e a defesa de suas causas foi sendo construída ao longo de seus percursos de trabalho, educação e militância. A busca por um trabalho em condições que não fossem de exploração e expropriação (de seus talentos, ideias e pautas) estava no horizonte de todos eles. Essas aspirações foram construídas em uma conjuntura específica do país - de ampliação dos níveis de escolarização da população outrora alijada da escola, de diminuição das desigualdades, de reconfiguração do mercado de trabalho.

Se, neste contexto, a realização de suas expectativas já era desafiadora e evidenciava os limites e as contradições que foram se acumulando na sociedade brasileira, no momento de realização da pesquisa o conjunto de moças e rapazes já reconhecia o quanto o contexto presente, de restrições de direitos, poderia impor obstáculos concretos de satisfação de suas perspectivas de trabalho. As reformas da legislação trabalhista e da Previdência Social foram mencionadas quase que espontaneamente como motivos de preocupação, porque representavam indícios da maior dificuldade a ser enfrentada por eles para acessar postos/ocupações 
promotores de uma vida digna e de um conjunto de direitos até agora assegurados aos trabalhadores. O cenário econômico e principalmente político inquietava os indivíduos, embora, ao menos no momento da pesquisa, não fosse capaz de asfixiar seus sonhos e iniciativas.

Tendo como referência a realidade europeia, José Machado Pais (2012) redigiu um artigo em que refletia sobre o fenômeno de gerações em situação de descrença ou de temor em relação ao futuro. Caracterizou como "disritmia" a descoincidência entre expectativas e percursos de vida, entre futuros imaginados e uma realidade que denega essas aspirações. É nesta tensão que interpreta a emergência de movimentos de indignação observados naquele período, especialmente protagonizados por jovens, que explicitavam descontentamento com o desemprego e a precariedade. Mas também a emergência de patologias e mal-estares suscitados pela frustração e pelo penoso sentimento de fracasso.

Podemos intuir que, após um período em que uma série de experiências sociais e biográficas permitiram a estes jovens vislumbrar futuros de realização pessoal e profissional, as mudanças recentes observadas no cenário econômico e político brasileiro projetem esses indivíduos para um presente em que o futuro não se deixa antecipar, em que a possessão do presente passa a representar a única alternativa a um pretenso tempo de espera e/ou de experimentação para um porvir. Talvez, tempos de incerteza, descrença e desilusão. Mas, como bem avalia Pais (2012):

enquanto para alguns jovens a posse do presente é pura fonte de prazeres imediatos, para outros é um tempo de fabricação de utopias, embora a natureza destas varie entre os que alimentam a esperança de as realizar e os que pensam que o importante não é realizar sonhos, mas ter sonhos por realizar (p. 277).

\section{Referências}

ABRAMO, Helena W. Cenas juvenis: punks e darks no espetáculo urbano. São Paulo: Scritta,1994.

ALMEIDA, W. O Prouni e o ensino superior lucrativo em São Paulo: uma análise sociológica. São Paulo: Musa, 2014.

BENEVIDES, M.R.T. O trabalho "flexível" no call center: da oportunidade à descartabilidade. In: Anais do IV Simpósio Lutas Sociais na América Latina, Londrina, 2010. 
BOURDIEU, P. A "juventude" é só uma palavra. In: BOURDIEU, P. Questões de sociologia. Lisboa: Fim do Século, 2003, p. 151-62.

BRASIL. Pesquisa Nacional por Amostra de Domicílios Contínua. IBGE. Brasília: 2018.

Disponível em:https://ww2.ibge.gov.br/home/estatistica/pesquisas/pesquisa_resultados.php?id_ pesquisa=149. Acesso em 02 de fev. 2019.

BRINGEL, B.; PLEYERS, G. Junho de 2013... dois anos depois. Nueva Sociedad (especial em português), out. 2015. Disponível em: http://nuso.org/articulo/junho-de2013-dois-anos-depois/. Acesso em 30 de jan. 2019.

CABANAS, P.; KOMATSU, B.; MENEZES FILHO, N. O crescimento da renda dos adultos e as escolhas dos jovens entre estudo e trabalho. São Paulo: Insper/Centro de Políticas Públicas, 2015.

CARVALHO, C. A política pública para a educação superior no Brasil (19952008): ruptura e/ou continuidade? 457 f. Tese (Doutorado), Instituto de Econômia UNICAMP, Campinas, 2011.

CORROCHANO, M.C. O trabalho e sua ausência: narrativas juvenis na metrópole. São Paulo: Annablume, 2012.

; DOWBOR, M.; JARDIM, F. Juventude e participação política no Brasil do século XXI: quais horizontes? Laplage em Revista. v. 4, n. 1, p.50-66, jan./abr. 2018.

; ABRAMO, H.W.; ABRAMO, L. O trabalho juvenil na agenda pública brasileira. Revista Latinoamericana de Estudios del trabajo. Buenos Aires:

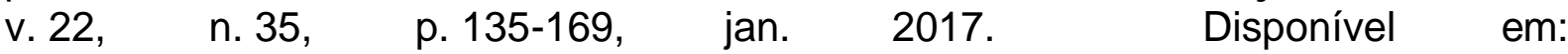
http://alast.info/relet ojs/index.php/relet/article/view/289/233. Acesso em 10 de fev. 2019.

CORSEUIL, C.H. A rotatividade dos jovens no mercado de trabalho formal brasileiro. In: CORSEUIL, C.H.; BOTELHO, R.U.(Orgs.). Desafios à trajetória profissional dos jovens brasileiros. Rio de Janeiro: Ipea, 2014.

CORTI, A.P.; CORROCHANO, M.C.; SILVA, J.A. "Ocupar e resistir": a insurreição dos estudantes paulistas. Educação e Sociedade, v. 37, n. 137, p. 1159-1176, out. 2016.

DEMAZIÈRE, D.; DUBAR, C. Analyser les entretiens biographiques: l'exemple des récits d'insertion. Paris: Nathan, 1997.

DUBET, F. Le déclin de l'institution. Paris: Ed. Seuil, 2002.

FERREIRA, V.S. Ser DJ não é só soltar o play: a pedagogização de uma nova profissão de sonho. Educação \& Realidade, [s.l.], n. 58, p. 71-108, set. 2008. 
- Milênios, gerações e geracionismos: pistas de um processo de transição geracional. In: FERREIRA, V.S.; LOBO, M.C.; ROWLAND, J.; SANCHES, E.R. Geração Milênio? Um retrato social e político. Lisboa: Instituto de Ciências Sociais, 2017, p. 39-78.

FRIGOTTO, G. Juventude, trabalho e educação no Brasil: perplexidades, desafios e perspectivas. In: NOVAES, R.; VANNUCHI, P. (Orgs). Juventude e sociedade: trabalho, educação, cultura e participação. São Paulo: Fundação Perseu Abramo/Instituto Cidadania, 2004, p. 180-216.

GOHN, M.G.; BRINGEL, B. Movimentos sociais na era global. Petrópolis, RJ: Vozes, 2012.

Jovens na política na atualidade: uma nova cultura da participação.

Caderno CRH, Salvador, v. 31, n. 82, p. 117-33, jan./abr. 2018.

GUIMARÃES, N. Trabalho: uma categoria-chave no imaginário juvenil? In: ABRAMO, H.W.; BRANCO, P.P. (Orgs.). Retratos da juventude brasileira: análises de uma pesquisa nacional. São Paulo: Fundação Perseu Abramo, 2005, p. 149-74.

; HIRATA, H.; SUGITA, K. Trabalho flexível, empregos precários? Reflexões a guisa de introdução. In: (Orgs.). Trabalho flexível, empregos precários? Uma comparação Brasil, França, Japão. São Paulo: Edusp, 2009, p. 924.

; MARTELETO, L.; BRITO, M.A. Transições e trajetórias juvenis no mercado brasileiro de trabalho: padrões e determinantes. Brasília: OIT, 2018.

HONNETH, A. A luta por reconhecimento: a gramática moral dos conflitos sociais. São Paulo: Editora 34, 2003.

KAUFMANN, J.-C. L’entretien compréhensif. Paris: Nathan, 1996.

KERGOAT, D. Le care et l'imbricationdesrapportssociaux. In: GUIMARÃES, N.A.; MARUANI, M.; SORJ, B. Genre, race, classe: travailler en France et au Brésil. Paris: Harmattan, 2016, p. 11-23.

LEITE, M.P.; SALAS, C. Trabalho e desigualdade sob um novo modelo de desenvolvimento. Tempo Social, São Paulo, v.26, n.1, p. 87-100, 2014.

LEITE, M.; BONO, A.D. El impacto de la tercerización y la deslocalización en el trabajo de telemarketing: una comparación entre Argentina y Brasil. Cadernos CHR, Salvador, v. 30, n. 79, p. 51-68, jan./abr. 2017.

LIMA, J. (Org.). Outras sociologias do trabalho: flexibilidade, emoções e mobilidades. São Paulo: EdUFSCAR, 2013.

LIMA, M.; PRATES, I. Desigualdades raciais no Brasil: um desafio persistente. In: ARRETCHE, M. Trajetórias das desigualdades: como o Brasil mudou nos últimos cinquenta anos. São Paulo: Ed. UNESP, 2015, p. 163-92. 
MARTUCCELLI, D. Cambio de rumbo: la sociedad a escala del individuo. Santiago: LOM Ediciones, 2007.

MELUCCI, A. A invenção do presente. Petrópolis: Vozes, 2001.

MÉSZÁROS, I. Para além do capital. São Paulo: Boitempo, 2002.

MARTINS, M.F.; GROPPO, L.A.; BARBOSA, J.R. Apresentação do dossiê temático: movimentos sociais conservadores e educação. Crítica Educativa, Sorocaba, v. 4, n. 2, p. 3-6, set./out. 2018 .

MOEHLECKE, S. Fronteiras da igualdade no ensino superior: excelência e justiça. 231 f. Tese (Doutorado), Faculdade de Educação -USP, São Paulo, 2004.

NASCIMENTO, É.P. Vozes negras e periféricas na literatura: pode o Estado amplificálas? In: Silva, C. (Org.). Africanidades e relações raciais: insumos para políticas públicas na área do livro, leitura, literatura e bibliotecas. Brasília: Ministério da Cultura/Fundação Palmares, 2014.

NONATO, S.P. Jovens [em] cena no palco da vida: percursos de individuação no entrecruzamento do mundo do trabalho com os processos de escolarização. 2019. 439 f. Tese (Doutorado), Faculdade de Educação - Universidade Federal de Minas Gerais, Belo Horizonte, 2019.

PAIS, J.M. A esperança em gerações de futuro sombrio. Estudos Avançados, São Paulo, v. 26, n. 75, p. 267-80, ago. 2012.

PLEYERS, G.; BENAVIDES, A.Á. La producción de la sociedad a través de los movimentos socials. Revista Española de Sociologia, Madri, n. 27, p. 1-9, 2018.

REGUILLO, R. Emergencia de culturas juveniles: estrategias del desencanto. Colombia: Norma, 2003.

Paisajes insurrectos: jovenes, redes y revueltas en el otoño civilizatorio. México: Ed. NED, 2017.

SILVA, F. A. Coletivos juvenis e transição para a vida adulta: desafios vividos por jovens da cidade de São Paulo. 2018. 230 f. Tese (Doutorado), Faculdade de Educação -USP, São Paulo, 2018.

SILVA, M.M. Inserção profissional de jovens: o circuito fechado da precarização.

Trabalho \& Educação, Belo Horizonte, v. 23, n. 3, p. 177-194, set. 2014.

SOARES, A. Tão longe, tão perto: o trabalho no setor de serviços. Revista Latino Americana de Estudos do Trabalho. Ano 16, n. 26, p. 89-117, 2011.

SOUZA, R. E depois da escola? Desafios de jovens egressos do ensino médio público na cidade de São Paulo. 2018. 353 f. Tese (Doutorado), Faculdade de Educação -USP, São Paulo, 2018. 
SPOSITO, M.P. Algumas reflexões e muitas indagações sobre as relações entre juventude e escola no Brasil. In: ABRAMO, H.W.; BRANCO, P.P.M. (Orgs). Retratos da juventude brasileira. São Paulo: Fundação Perseu Abramo/Instituto Cidadania, 2005, p. 87-127.

SPOSITO, M.P. Ação coletiva, jovens e engajamento militante. In: CARRANO, P.; FÁVERO, O. Narrativas juvenis e espaços públicos: olhares de pesquisa em educação, mídia e ciências sociais. Niterói: UFF, 2014. p. 97-130.

; SOUZA, R.; SILVA, F.A. A pesquisa sobre jovens no Brasil: traçando novos desafios a partir de dados quantitativos. Educação e Pesquisa, [s.l.], v. 44, p.1-24, dez. 2017.

TARABOLA, F. Aspirantes: desafios de estudantes da USP egressos de escolas públicas no contexto do novo tensionamento político-social brasileiro. 2015. 417 f. Tese (Doutorado), Faculdade de Educação -USP, 2017.

TARTUCE, G. Jovens na transição escola-trabalho: tensões e intenções. São Paulo: Annablume, 2010.

TOMMASI, L; VELAZCO, D. A produção de um novo regime discursivo sobre as favelas cariocas e as muitas faces do empreendedorismo de base comunitária. Revista do Instituto de Estudos Brasileiros, Brasil, n. 56, p. 15-42, jun. 2013. 